\title{
O CONHECIMENTO EM HUME E CARNAP: CONVERGÊNCIAS E APROXIMAÇÕES
}

\author{
JOSÉ APARECIDO PEREIRA \\ PUC-PR. Doutor em Filosofia pela PUC/SP. E-mail: aparecido.pereira@pucpr.br \\ CV: http://lattes.cnpq.br/8583907984500271
}

Artigo submetido em Fevereiro/2016 e aceito em Julho/2016

\section{RESUMO}

Fazer uma abordagem na qual sejam estabelecidas aproximações e convergências entre filosofia empirista de David Hume e a epistemologia de Carnap constitui-se como o objetivo fundamental desse artigo. No decorrer desse estudo veremos que os pontos mais convergentes entre ambos se encontram em relação à postura antimetafísica que perpassa as suas doutrinas. Hume não é favorável ao conhecimento puramente especulativo, justamente porque esse parece não se coadunar com aquilo que ele denomina de relações de idéias e relações de fato. Por sua vez, Carnap pretende, aos moldes de Hume, uma eliminação radical da metafísica do âmbito da ciência, utilizando-se de um instrumental poderoso: a análise lógica da linguagem, com a qual acreditava dar uma nova resposta à questão da validade e justificação da metafísica.

PALAVRAS-CHAVE: Ciência. Metafísica. Hume. Carnap. Conhecimento.

\section{THE KNOWLEDGE IN HUME AND CARNAP: CONVERGENCES AND APPROXIMATIONS}

\section{ABSTRACT}

The main aim of this article was to make an approach in which similarities and convergences were established between David Hume's empiricist philosophy and Carnap's epistemology. During this study we observed that the main convergent points between them were in relation to the anti-metaphysical attitude which permeates their doctrines. Hume is not favorable to the purely speculative knowledge, especially because that does not seem to mesh with what he names relations of ideas and relations of fact. On the other hand, Carnap seeks, in line with Hume, a radical elimination of metaphysics from the scope of science, using a powerful instrument: the logical analysis of language, with which he believed to give a new answer to the question of the validity and justification of metaphysics.

Keywords: Science. Metaphysics. Hume. Carnap. Knowledge. 


\section{INTRODUÇÃO}

Pode-se afirmar que os dois aspectos fundamentais nas discussões acerca da filosofia da ciência contemporânea são a coerência lógica dos enunciados e das teorias e uma base empírica que dê sustentação ao conhecimento e que sirva de fundamento para toda expressão que tange a realidade. Na ausência de um desses princípios básicos não é possível o conhecimento científico legítimo acerca do mundo, ou pelo menos, é impossível uma justificação última do que se conhece. Desse modo, a importância atribuída à lógica na constituição desse tipo de conhecimento provém, sobretudo, da influência exercida pela filosofia de Wittgenstein. Esse autor pensava que a filosofia não deveria ser concebida como um corpo doutrinário, mas como uma atividade que visa à elucidação lógica do pensamento. Ele restringe, portanto, antes mesmo de Carnap, a tarefa da filosofia a uma análise lógica da linguagem. Mas, e quanto à influência do outro princípio fundamental para a filosofia da ciência, qual seja a base empírica como fundamento? Que influências foram determinantes para que os neopositivistas ou positivistas lógicos adotassem esse como um dos princípios básicos de sua filosofia?

A importância da experiência como fundamento para a constituição do conhecimento legítimo ou verdadeiro acerca da realidade (ou a constituição de uma base empírica para o conhecimento) provém, como já era de se suspeitar, do empirismo clássico. No entanto, é preciso ressaltar que, dentre as diversas faces dessa concepção, a filosofia humeana se destaca por apresentar uma crítica ferrenha à metafísica e um critério de significado e verdade muito próximo daquele que, posteriormente, os neopositivistas, sobretudo Carnap, chamariam de critério de demarcação verificacionista entre ciência e metafísica. Portanto, é a partir desses elementos que pretendemos demonstrar, nesse artigo, os pontos convergentes entre o empirismo de Hume e os postulados que fundamentam a visão de ciência de Carnap. Mas antes de efetivarmos esse objetivo, faz-se necessário uma abordagem sobre os elementos que caracterizam e explicitam a gênese e a formação do Círculo de Viena, haja vista que Carnap é considerado o seu maior representante.

\section{GÊNESE E CARACTERIZAÇÃO DO CÍRCULO DE VIENA}

As discussões sobre a filosofia da ciência surgiram por volta da década de vinte do século passado em Viena na Áustria, quando um grupo de filósofos e cientistas, liderados por Moritz Schlick e influenciados pela teoria do significado contida no Tractatus Lógico-Philosophicus (2001) de Ludwig Wittgenstein, passaram a se reunir frequentemente para discutir temas relativos ao conhecimento científico. ${ }^{1} \mathrm{O}$ propósito era o desenvolvimento de um projeto no qual emergiria uma nova fundamentação para

\footnotetext{
${ }^{1} \mathrm{O}$ grupo era constituído por estudiosos de áreas diferentes, sobretudo, por jovens com doutorado na área da filosofia, mas que também transitavam nas áreas da matemática e das ciências sociais. Dentre os seus membros alguns nomes podem ser mencionados, tais como, Phillip Frank, Hans Hahn, Richard von Mises e Otto Neurath. Eles se reuniam todas às sextas-feiras no período noturno como intuito de promover uma discussão sobre questões relacionadas ao conhecimento científico.
}

Dialektiké, v. 2, 2016. p. 36-47 
as teorias científicas assentadas em uma linguagem lógica. Portanto, a pretensão era fundamentar na lógica uma ciência empírico-formal da natureza e aplicar métodos lógicos e rigor científico na abordagem de questões relacionadas à moral, à psicologia e às ciências sociais, principalmente na sociologia e na economia. Uma das características mais elementares do chamado Círculo de Viena foi o seu veemente combate ao pensamento metafísico especulativo. Por causa disso, a física, nesse projeto teórico, apareceria como o grande paradigma de cientificidade para todas as teorias que reivindicassem para si o estatuto de ciência, formulando em um discurso lógico, rigoroso e preciso verdades objetivas sobre o real. Soma-se a isso a pretensão de instaurar um projeto geral no qual a ideia fundamental consistia em mostrar como as leis científicas poderiam ser reformuladas em uma linguagem fisicalista. Assim, as teorias deveriam estar ancoradas por princípios fornecidos pela lógica, de cunho analítico, isto é, verdadeiros em função de sua própria forma lógica e de seu significado. Em vista disso, as pesquisas neopositivistas e, sobretudo, as discussões em torno da ciência eram articuladas e desenvolvidas a partir de várias temáticas, dentre as quais podemos destacar: a busca de um fundamento do conhecimento, a natureza da realidade, determinismo, acaso, limites do conhecimento, critérios de verdade, critérios de demarcação entre ciência e não-ciência, origem do conhecimento científico, metodologia científica e outros. Dentre esses temas, vamos nos concentrar no problema que durante muito tempo ocupou os neopositivistas: o problema relativo à determinação de um bom critério de demarcação entre ciência e não-ciência ou metafísica, um dos assuntos centrais e mais problemáticos de toda filosofia da ciência contemporânea.

Antes de concretizarmos o objetivo fundamental desse artigo, acreditamos ser importante e necessária uma abordagem sobre os antecedentes históricos e as influências teóricas que possibilitaram a formação do arcabouço teórico do pensamento neopositivista sobre o conhecimento científico. Luiz Carlos Bombassaro, em seu livro As Fronteiras da Epistemologia, apresenta-nos as raízes da chamada tendência analítica da filosofia da ciência da seguinte maneira:

As raízes da tendência analítica podem ser situadas como originárias de múltiplas contribuições teóricas. Dentre elas, num primeiro momento, podemos citar: a concepção de significado e verdade defendida por David Hume; o monismo metodológico do positivismo de Augusto Comte e John Stuart Mill; o radical fenomenalismo de Ernest Mach e Richard Avenarius; as conclusões de Gottlob Frege nos campos da lógica e da semântica; o desenvolvimento da lógica e da filosofia da matemática operadas por Alfred Withehead e Bertrand Russell; o formalismo de David Hilbert, e, principalmente, a teoria do significado contida no Tractatus LógicoPhilosoplhicus de Ludwig Wittgenstein. (BOMBASARO, 1992, p. 26 )

Convém dizer que essas são apenas algumas das muitas influências teóricas talvez as mais importantes - recebidas pelos filósofos da tendência analítica da filosofia da ciência. Mas é importante também levar em consideração o contexto histórico a partir do qual ocorreu a gênese do Círculo de Viena. Influenciada pelo arcabouço cultural alemão, na cidade de Viena, no final do século XIX e início do século XX, aconteceram mudanças de significativas proporções em diversos campos do saber humano desde a arquitetura, 0 
jornalismo, a arte, a poesia, a música até o teatro. Diversas perspectivas filosóficas também se encontravam muito difundidas, sobretudo os pressupostos teóricos da filosofia transcendental de Kant e os postulados do idealismo alemão delineados por Fichte, Schelling e Hegel, bem como as ideias pertencentes ao Romantismo. Investigações sobre o avanço e o progresso do conhecimento científico nesse período demonstram claramente que a cidade de Viena se encontrava a mercê de aspectos ideológicos que privilegiavam a razão, a ordem e o progresso. É nesse contexto que emergiu no pensamento contemporâneo o Círculo de Viena. Embora tivessem uma visão consensual sobre os aspectos mais fundamentais que deveriam orientar as atividades intelectuais do grupo, nem sempre as posições quanto aos critérios de aplicação e inferências sobre o conhecimento científico convergiam para a unanimidade, estabelecendo-se muitas vezes polêmicas e conflitos.

Enfim, o que importa daqui para frente, tendo em vista os propósitos desse artigo, é que reflitamos sobre os pressupostos teóricos fundamentais que se aproximam ou se mostram convergentes entre as concepções de conhecimento de Hume e de Carnap. Nesse sentido, de antemão, já destacamos dois pontos interessantes, a saber: o caráter antimetafísico e a chamada concepção de significado e verdade. Portanto, nas linhas seguintes, a nossa pretensão consiste em demonstrar como é possível estabelecer tais convergências e aproximações entre esses dois pensadores.

\section{CONVERGÊNCIAS E APROXIMAÇÕES ENTRE O CONHECIMENTO EM HUME E CARNAP}

Iniciemos a nossa análise fazendo referência a um ponto comum não somente entre Hume e Carnap, mas também entre os partidários do Círculo de Viena: a objeção ao pensamento metafísico. Como sabemos, a metafísica como uma ciência que investiga as causas últimas e a essência do ser e da realidade ou como aquela que indaga sobre os primeiros princípios e as causas primeiras de todos os seres, encontra-se enraizada no âmbito da filosofia grega e foi rigorosamente sistematizada como ciência por Aristóteles. Assim, a realidade investigada pelo pensamento metafísico é aquela que deve se enquadrar ou adequar às regras lógicas da razão, ou seja, uma realidade explicada e compreendida tendo como fundamento o pensamento. No segundo prefácio da Crítica da razão pura (2013) Kant faz alusão à metafísica caracterizando-a como um saber marcadamente especulativo por ultrapassar o domínio da experiência no qual a razão é discípula de si mesmo. Na sua visão, de todas as ciências a metafísica é a mais antiga.

Através do seu projeto intitulado ciência da natureza humana, inspirado na física de Newton, as pretensões de Hume consistiram em fundamentar a sua teoria do conhecimento na experiência, levando o empirismo a uma versão radical. Ao fazer isso, ele se distanciou significativamente das discussões marcadamente metafísicas postuladas no decorrer da história da filosofia em torno desse assunto. Ele se posicionará muito criticamente quanto às pretensões da metafisica em encontrar um fundamento último para o problema do conhecimento. Dessa maneira, antes de rejeitar essas pretensões do pensamento metafísico, Hume se propôs a diagnosticar as motivações da desvalorização generalizada das suas especulações. O seu descrédito em relação ao raciocínio metafísico ocorreu quando ele descobriu que os seus argumentos possuíam uma má fundamentação enquanto um sistema filosófico, devido a uma aceitação inteiramente cega dos princípios onde os fundamentos 
recaem em diversas incoerências e inconsistências: "Princípios acolhidos com base na confiança; consequências deles deduzidas de maneira defeituosa; falta de coerência entre as partes, e de evidência no todo [...] É daí que surge em minha opinião, o preconceito comum contra todo tipo de raciocínio metafísico" (HUME, 2009, p.19-20). Dessa maneira, o empirismo de Hume estabeleceu novas perspectivas para as discussões em torno da metafísica, fazendo com que esse domínio tivesse as suas bases teóricas abaladas, o que para muitos estudiosos significou não somente um momento de crise, mas também de ruptura com o pensamento racionalista muito acentuado na modernidade a partir de Descartes, que pensava a fundamentação do conhecimento em bases metafísicas.

As objeções de Hume em relação ao modo metafísico de abordar questões epistemológicas se encontram tanto no Tratado da natureza humana (2009) quanto nas Investigações sobre o entendimento humano (1989). No Tratado ele sustenta que, a imperfeição das especulações metafísicas é perceptível até mesmo por aqueles que não estão envolvidos com tais discussões: "Mesmo a plebe lá fora é capaz de julgar, pelo barulho e vozerio que ouve, que nem tudo vai bem aqui dentro" (HUME, 1989, p.19). Dessa maneira, para Hume, a metafísica se transformou num palco no qual as disputas se multiplicam e se tornam cada vez mais acirradas. Essa situação leva a própria filosofia a um distanciamento do seu objetivo último, qual seja a busca da verdade. Assim, "Multiplicam-se as disputas, como se tudo fora certo; e essas disputas são conduzidas da maneira mais acalorada, como se tudo fora certo. Em meio a todo esse alvoroço, não é a razão que conquista os louros, mas a eloquência" (HUME, 1989, p.20). A insatisfação de Hume quanto ao modo como se discutia o problema do conhecimento a partir da perspectiva metafísica também pode ser observada através da seguinte passagem:

\begin{abstract}
Aqui reside, de facto, a objeção mais justa e mais plausível contra uma considerável parte da metafísica, que não é verdadeiramente uma ciência, mas brota ou dos esforços infrutíferos da vaidade humana, que penetraria em matérias totalmente inacessíveis ao entendimento, ou da esperteza das superstições populares que, sendo incapazes de se defender a si mesmas de um modo justo, suscitam este emaranhado de silvas para ocultar e proteger as suas fraquezas. (HUME, 1989, p. 18)
\end{abstract}

Mas uma distinção importante na epistemologia de Hume servirá de referencial teórico para demonstrar ainda mais a sua insatisfação quanto ao pensamento metafísico. Trata-se da conhecida distinção entre relação de ideias ${ }^{2}$ e questão de fato. A primeira inclui os princípios de semelhança, grau ou qualidade, contrariedade e quantidade ou número. Essa classe é inteiramente dependente das ideias e estão contidas nas verdades da matemática e nas ciências formais. Sendo assim, ela somente considera as ideias que passam por um processo de comparação, incluindo objetos do conhecimento que envolve determinada certeza e constância. Quanto às proposições desse tipo de relação, Hume salienta o seguinte: "[...] podem descobrirse pela simples operação do pensamento, sem dependência do que existe em alguma parte

\footnotetext{
${ }^{2}$ Como afirma Noonan, "visto que idéias são significados, uma proposição baseada nas relações de ideias são aquelas que são verdadeiras por refletir o significado das palavras usadas para expressá-la. Todo solteiro é um homem não-casado, é um exemplo paradigmático deste tipo de proposição - uma proposição analítica como designamos atualmente" (NOONAN, 1999, p. 100; itálico do autor)
} 
no universo" (HUME, 1989, p. 31). Por sua vez, a questão de fato é de natureza totalmente diferente por serem extremamente dependentes da experiência, constituindo-se como a condição fundamental para investigar o problema da causalidade. Por conta disso, elas se situam no âmbito das ciências empíricas. Em relação à questão de fato Hume afirma o seguinte: "Todos os raciocínios relativos à questão de facto (matter of fact) parecem fundar-se na relação de Causa e Efeito" (HUME, 1989 , p. 32). A distinção entre relação de ideias e questão de fato proposta por Hume também explicitam elementos que constituem sérios problemas para o pensamento metafísico. Ao constatar isso, o filósofo se pronuncia nestes termos:

Ao passarmos os olhos pelas bibliotecas, persuadidos destes princípios, que devastação devemos fazer? Se pegarmos num volume de teologia ou de metafísica escolástica, por exemplo, perguntemos: Contém ele algum raciocínio acerca da quantidade ou número? Não. Contém ele algum raciocínio experimental relativo à questão de fato e à existência? Não. Lançai-o às chamas, porque só pode conter sofisma e ilusão. (HUME, 1989, p. 156; itálico do autor)

Por meio da passagem acima podemos inferir que Hume expressa uma postura nenhum pouco favorável ao conhecimento puramente especulativo, justamente porque esse parece não se coadunar ou se alinhar com aquilo que ele denominou de relações de idéias e questão de fato. Embora tenha elaborado a distinção entre relação de ideias e questão de fato para discutir o problema da causalidade, Hume acabou instituindo um critério muito interessante para se definir quando uma proposição metafísica possui um caráter científico ou não. Nesse sentido, a partir da formulação de tal critério ou distinção, a seu ver, as especulações ontológico-metafísicas não poderão ser consideradas como proposições científicas ou epistemológicas. Desse modo, podemos abstrair dessa postura de Hume uma inquietante crítica à metafísica, levada ao extremo de não lhe conferir relevância para a constituição ou justificação do conhecimento.

Ora, essa visão de Hume estará muito próxima da crítica que veremos reaparecer nas concepções de um dos maiores representantes do Círculo de Viena, Rudolf Carnap. Em seu artigo Eliminação da metafísica por meio da análise lógica da linguagem (1965) ele pretendeu demonstrar, aos moldes de Hume, não somente uma crítica ao pensamento metafísico, mas também uma eliminação radical e definitiva da metafísica do âmbito da ciência, utilizando-se de um instrumental poderoso: a análise lógica da linguagem. Ao fazer isso, Carnap procurou dar uma nova resposta à questão da validade e justificação da metafísica. Dessa maneira, nas duas passagens a seguir, podemos constatar elementos relevantes que nos mostram explicitamente que, assim como Hume, Carnap se posicionou claramente como um antimetafísico:

Na primeira temos o que segue:

Não apenas o leitor, mas também o metafísico mesmo sofre a ilusão de que por meio das proposições metafísicas, declara-se algo, descreve-se uma situação objetiva. O metafísico crê mover-se no terreno do verdadeiro e do falso, quando na realidade não tem afirmado nada, mas apenas tem expressado algo como um artista. (CARNAP, 1965, p. 86) 
Na segunda:

Uma proposição afirma somente tudo que com respeito a ela resulta verificável. Por isso, uma proposição quando diz algo só pode enunciar um fato empírico. Algo que estivesse além do experimentável, não poderia ser dito, nem pensado, nem colocado. (CARNAP, 1965, p. 82)

Das duas citações acima, de maneira especial, a segunda parece deixar bem explícito o porquê Carnap se posicionou de modo muito reticente e contrário ao pensamento metafísico. A citação indica uma espécie de critério ou condição segundo a qual as especulações metafísicas jamais poderiam ser concebidas como proposições científicas. $E$, coincidentemente ou não, tal condição se encontra bem alinhada com o que Hume propôs a partir da sua distinção entre relação de ideias e questão de fato. Vimos ainda a pouco que um dos problemas levantado por Hume quanto aos postulados da metafísica se encontrava em relação à questão de fato, cujo domínio é o da experiência ou do empírico. Ou seja, na sua interpretação a metafísica não pode trabalhar com questão de fato porque as suas entidades não se restringem ao âmbito físico e sensorial, ou porque as suas ideias não têm impressões e sensações correspondentes. Portanto, essa foi uma das suas motivações que o levou a elaborar argumentos que demonstrassem as inconsistências da metafísica. Ora, o que vemos no pensamento de Carnap, por meio da segunda citação que apresentamos acima, é praticamente a sugestão da mesma condição ou requisito que fez Hume para a aceitação da metafísica no âmbito do conhecimento.

Se retomarmos as duas grandes obras de Hume, o Tratado da natureza humana (2009) e a Investigação sobre o entendimento humano (1989), podemos contemplar a instituição de um critério para se definir quando uma ideia na mente é portadora de significado e verdade. Mas antes de demonstrar tal critério é necessária uma abordagem sobre o modo como o pensador explica a relação entre impressões e ideias na sua teoria da percepção. Isso é preciso porque o critério de significado e verdade proposto por Hume está relacionado a essa explicação e discussão. Duas passagens, uma das Investigações e a outra do Tratado, explicitam claramente a relação entre impressões e ideias na epistemologia de Hume. Na primeira, o filósofo se posiciona do seguinte modo:

Podemos, pois, dividir aqui todas as percepções da mente em duas classes ou tipos, que se distinguem pelos seus diferentes graus de força e vivacidade. As menos intensas e vivas são comumente designadas Pensamentos (thoughts) ou Ideias (ideas). O outro tipo [...] chamemosIhe impressões (impressions) (HUME, 1989, p. 24)

Por sua vez, na segunda, Hume afirma: 
As percepções da mente humana se reduzem a dois gêneros distintos, que chamarei de IMPRESSÕES e IDÉIAS. A diferença entre estas consiste nos graus de força e vividez com que atingem a mente e penetram em nosso pensamento ou consciência (HUME, 2009, p.25; maiúsculas do autor).

É dessa forma, portanto, que Hume descreve a origem de nossas ideias ou pensamentos, ou seja, dividindo as percepções em duas espécies de acordo com seus graus de força e vivacidade ${ }^{3}$ e reduzindo as menos vivazes (ideias ou pensamentos) às mais vivazes (impressões). Temos assim, o primeiro princípio da doutrina de Hume acerca da natureza humana, o princípio da cópia, expresso no Tratado da seguinte forma: "Primeiramente, uma impressão atinge os sentidos, fazendo-nos perceber o calor ou o frio, a sede ou a fome, o prazer ou a dor, de um tipo ou de outro. Em seguida, a mente faz uma cópia desta impressão, que permanece mesmo depois que a impressão desaparece, e à qual denominamos ideia". (HUME, 2009, p. 32)

Assim, o princípio da cópia é o fundamento do chamado critério de significado e verdade defendido por Hume em sua obra e que, conforme nos diz Bombassaro, compõe uma das principais raízes da tendência analítica da filosofa da ciência contemporânea. Tendo formulado esse critério, Hume pensa que bastaria aplicá-lo a todos aqueles termos que comportam certa ambiguidade ou obscuridade para, dessa forma, chegarmos a uma resposta última sobre o significado dos mesmos. $O$ autor aplicará seu critério, por exemplo, a conceitos metafísicos tais como conexão necessária, força, poder e eficácia ${ }^{4}$, dos quais muitos filósofos se utilizam na tentativa de explicar a suposta causalidade existente entre os objetos. Assim, Hume acredita poder especificar o significado preciso dos termos, reduzindoos às impressões sensíveis, mediante o princípio da cópia. Vejamos, a título de exemplo, como o autor descreve seu método para estabelecer o significado na Investigação sobre o entendimento humano:

\footnotetext{
${ }^{3}$ Segundo Hume, todas as percepções da mente se dividem em impressões e idéias, podendo ser diferenciadas pelos graus de força e vivacidade com que se apresentam à mente. As impressões (sensações, paixões, emoções) se apresentam com maior força, enquanto que as idéias são mais fracas e débeis. A diferença entre ambas pode ser, grosso modo, estabelecida mediante a distinção entre sentir e conceber. Podemos dividi-las ainda em percepções simples e complexas. As primeiras não admitem distinção, enquanto as outras podem ser divididas em partes. "Embora uma cor, um sabor e um aroma particulares sejam todos qualidades unidas nesta maçã, é fácil perceber que elas não são a mesma coisa, sendo menos distinguíveis umas das outras". (HUME, 2009, p. 26)

“ Cabe lembrar que os termos "eficácia”, "agência”, "poder", "força”, "energia”, "necessidade”, "conexão" e "qualidade produtiva" são sinônimos para Hume. Desta forma, não é legítimo definir qualquer um deles por meio dos demais, como fazem erroneamente alguns filósofos. "Com essa observação rejeitamos, de uma só vez, todas as definições comuns que os filósofos dão para poder e eficácia. Em vez de procurar a ideia nessas definições, devemos procurá-las nas impressões de que originalmente deriva" (HUME, 2009, p.189-190). Além disso, vale lembrar que - como afirma Hume, na seção VII das Investigações - "Das ideias que ocorrem na metafísica não há mais obscuras e incertas do que as de poder, força, energia ou conexão necessária, das quais nos é indispensável tratar em cada momento, em todas as nossas disquisições". (HUME, 1989, p. 64). Já no Tratado o autor refere-se a este tema advertindo que se trata de "uma das questões mais sublimes da filosofia [...] e a qual parece ser objeto de tamanho interesse por parte de todas as ciências" (HUME, 2009, p. 189).
}

Dialektiké, v. 2, 2016. p. 36-47 
Quando alimentarmos alguma suspeita de que um termo filosófico é empregue sem um significado ou ideia (como acontece com demasiada frequência), precisamos apenas de perguntar: de que impressão deriva esta suposta ideia? E se for impossível assinalar alguma, isso servirá para confirmar a nossa suspeita (HUME, 1989, p. 27)

Podemos dizer que essa citação expressa dois aspectos importantes da epistemologia de Hume. Em primeiro lugar, ele corrobora a sua afirmação segundo a qual as ideias são derivadas ou oriundas das impressões. Portanto, a sua gênese possui uma estreita relação com a experiência. Entretanto, o aspecto mais importante dessa citação, por estar relacionado ao que estamos discutindo nesse momento (à questão do significado), é a sua convicção de que o significado de uma ideia somente pode ser definido a partir da sua relação ou correspondência com a impressão. Desse modo, podemos afirmar que Hume institui um critério fundamental para que uma ideia seja portadora de sentido e de significado e, por consequência, seja entendida como verdadeira: "[...] que todas as ideias são apenas cópias das nossas impressões ou, por outras palavras, que nos é impossível pensar qualquer coisa que previamente não tenhamos sentido, quer pelos nossos sentidos externos ou internos" (HUME, 1989, p. 64-65).

E Carnap, o que estaria sugerindo com o emprego da palavra significado? Que critério utilizou para estabelecer uma clara demarcação entre enunciados com significado e enunciados sem significado? Para responder a essas questões precisamos considerar que, segundo ele, é possível especificar o significado das palavras ou sentenças mediante a chamada redutibilidade ou dedutibilidade que consiste no fato de estabelecermos como uma palavra ocorre em sua forma sentencial mais simples ou elementar, como ele próprio explica na citação a seguir:

Em primeiro lugar, a sintaxe da palavra deve ser fixada, isto é, o modo de sua ocorrência na forma sentencial mais simples na qual é capaz de ocorrer; denominamos esta forma sentencial sua sentença elementar. A forma sentencial elementar para, por exemplo, a palavra "pedra" é "x é uma pedra"; em sentenças dessa forma, alguma designação da categoria das coisas ocupa o lugar de " $x$ ", por exemplo, "este diamante", "esta maça" etc (CARNAP, 1965, p. 68)

A partir dessa redução das sentenças àquelas sentenças ainda mais elementares (aquelas sentenças ou proposições fatuais que figuram na base do conhecimento) chegamos ao significado das palavras. Há aqui o que Carnap chama também de uma dedutibilidade, uma vez que, as sentenças são deduzidas (ou dedutíveis) dessas sentenças elementares ou sentenças de observação, que expressam o dado. ${ }^{5}$ Enfim,

\footnotetext{
${ }^{5}$ Vale ressaltar que, embora Carnap afirme que as chamadas proposições de observação refiram-se ao "dado", está consciente das dificuldades que este conceito envolve (O que é o dado? Estas proposições realmente o representam?). No entanto, o autor não acredita ser oportuno se envolver com esta problemática que, para ele, constitui um insolúvel problema metafísico. Para seus propósitos, basta considerar que isto é o que nossas
} 
mesmo que seja questionável essa maneira de conceber a determinação do significado das palavras e sentenças, o que importa é que temos em Carnap, um exemplo claro do chamado critério de verificabilidade neopositivista. Segundo Carnap existem dois grandes problemas que a teoria do conhecimento deve ser ocupar: a questão da significação e a questão da verificação. O critério da verificabilidade constitui-se como um referencial fundamental cujo objetivo consiste em estabelecer quando uma sentença dada pode ser considerada verdadeira ou falsa. Portanto, ele tem como foco a validade das sentenças.

Desse modo, a chamada redutibilidade ou dedutibilidade (ou mesmo critério de aplicação, como o autor gostava de chamar) nada mais é que um critério de significado acerca de nossos enunciados sobre a realidade, capaz, segundo o pensador, de demarcar, com precisão, formulações com sentido (próprias das ciências - sejam elas formais ou empíricas) das formulações sem sentido (da metafísica, da teologia, da poesia etc). No que diz respeito à redutibilidade Carnap também afirma o seguinte: "Justifica-se o conteúdo de uma certa cognição relacionando-a aos conteúdos de outras cognições que se supõem serem válidas. Assim, um conteúdo é reduzido a outro". ${ }^{6}$ Para o autor, o sentido ou significado de uma sentença deve estar relacionado ao que ele chamou de estado de coisas. Na ausência dessa condição é impossível a atribuição de significado para qualquer enunciado ou sentença.

Após apresentar a aplicação de seu critério às sentenças que ocorrem nas ciências empíricas para especificar o significado das palavras, bastaria aplicá-lo também àquelas sentenças que ocorrem na metafísica para, assim, especificar o significado de palavras como ideia, princípio, incondicionado, Deus, ser e assim por diante. Para o pensador, essa aplicação resultaria na eliminação da metafísica, uma vez que as palavras e enunciados nos quais elas ocorrem, não podem ser reduzidos a sentenças elementares ou proposições de observação que expressam o dado. Dessa maneira, Carnap sustenta que apenas aqueles enunciados que manifestam conteúdos relacionados a dados sensoriais são teoricamente portadores de significado. Em contrapartida, aqueles que não se encaixam nessa condição são totalmente carentes de sentido e significado: "Somente os enunciados que possuem conteúdo factual são teoricamente significativos; enunciados (ostensivos) que não podem em princípio, estar fundamentados pela experiência são carentes de significado" (CARNAP, 1980, p. 168).

A partir disso, podemos afirmar que para Hume o significado de uma ideia deve ter relação com a experiência. Também para Carnap o significado de um enunciado depende da sua relação com a experiência. ${ }^{7}$ Assim, para ambos a experiência deve ser a condição sem a qual qualquer enunciado ou ideia estariam desprovidos de sentido e significado. Portanto, podemos dizer que o posicionamento humeano que influenciou fortemente os

\footnotetext{
limitadas capacidades cognitivas podem nos fornecer. Não podemos ir além destas proposições, que constituiriam, por assim dizer, o fundamento do conhecimento.

${ }^{6}$ CARNAP, 1965, p. 69

${ }^{7}$ Segundo Hessen, o problema de uma concepção empirista do significado como a de Hume e, posteriormente, como a dos empiristas lógicos como Carnap, é que "o conhecimento humano fica encerrado de antemão dentro dos limites do mundo empírico" (HESSEN, 1980, p. 73). Com essa afirmação, o autor está sugerindo que o empirismo substitui o extremo do racionalismo por um outro extremo, tão perigoso quanto aquele. Nenhuma das posições é capaz de visualizar e compreender a riqueza da relação mútua entre subjetividade (razão) e experiência (influência objetiva).
} 
neopositivistas tem, em seu escopo, um critério de significado muito preciso que, embora não possamos denominá-lo ainda um verdadeiro critério de verificabilidade, tem características análogas àquelas assumidas pelos defensores contemporâneos deste critério, ou seja, os pensadores neopositivistas dentre os quais Carnap é comumente considerado como o seu maior representante. Enfim, acreditamos que esses aspectos explicitam claramente as relações de convergências e aproximações entre o critério de significado de Hume e seu fundamento no chamado princípio da cópia e o critério de significado neopositivista e seu fundamento na verificabilidade dos enunciados proposto e defendido por Carnap. Desse modo, além de apontar aproximações e convergências, o que intentamos ter esclarecido com esse confronto entre os dois autores foi a pretensão comum em torno de um critério que pudesse questionar as pretensões da metafísica com o intuito de não a conceber como fundamento para o conhecimento.

\section{CONSIDERAÇÕES FINAIS}

Podemos concluir, a partir das discussões anteriores, que tanto para o empirismo humeano quanto para o fisicalismo carnapiano, a única fonte legítima de conhecimento acerca da natureza está na experiência. Assim, não resta qualquer espaço à razão a priori na origem e constituição de nossas ideias ou pensamentos. Para esses autores, mesmo os conceitos mais gerais ou abstratos procedem da experiência sensível e são redutíveis a ela. Para defender essa posição, eles e outros empiristas, precisam proceder das ciências naturais ou empíricas.

Hume, por exemplo, entusiasmado com os expressivos resultados da física newtoniana, acreditava que seu Tratado da natureza humana poderia ser descrito enquanto uma tentativa de introduzir o método experimental de raciocínio (próprio das ciências naturais) nos assuntos morais (política, moral, religião). Enfim, trata-se de comprovar exatamente os fatos, mediante cuidadosa observação, como ocorre nas ciências empíricas. Assim, à metafísica, inevitavelmente, não mais estaria a função de justificar problemas epistemológicos, pois para serem justificados, todos os conceitos e enunciados sobre a realidade devem reduzir-se a qualquer coisa dada no âmbito empírico. É isso que faz Hume, ao abandonar, por exemplo, conceitos importantes da metafísica tradicional, tais como, substância e causalidade.

\section{REFERÊNCIAS}

BOMBASSARO. L. C. As Fronteiras da Epistemologia: uma introdução ao problema da racionalidade e da historicidade do conhecimento. Petrópolis, Rio de Janeiro: Vozes, 1992.

CARNAP, R. La Superación de la Metafísica Mediante el Análisis Lógico del Lenguaje. In: AYER, A. J. (org.) El Positivismo Lógico. México: Fondo de Cultura Econômica, 1965.

HESSEN, J. Teoria do Conhecimento. Trad. Dr. Antônio Correia $7^{\mathrm{a}}$ ed. Coimbra-Portugal: Armênio Amado Editor, 1980. 
HUME, David. Investigação Sobre o Entendimento Humano. Trad. de Artur Morão. Lisboa: Edições 70, 1989, p. 31

Tratado da Natureza Humana. Trad. Déborah Danowski. São Paulo: Editora UNESP, 2009.

KANT. I. Crítica da razão pura. Lisboa: Fundação Calouste Gulbenkian, 2013NOONAN. Harold W. Hume: On Knowledge. London and New York: Routledge. 1999.

SCHLICK, M \& CARNAP, R. Seleção de Pablo Rubén Mariconda. Trad. Luiz João Baraúna, Pablo Rubén Mariconda. São Paulo: Abril Cultural, 1980.

WITTGENSTEIN, Ludwing. Tractatus Lógico-Philosophicus. São Paulo: EDUSP, 2001 